Article

\title{
Further Evidence That Defects in Main Thyroid Dysgenesis-Related Genes Are an Uncommon Etiology for Primary Congenital Hypothyroidism in Mexican Patients: Report of Rare Variants in FOXE1, NKX2-5 and TSHR
}

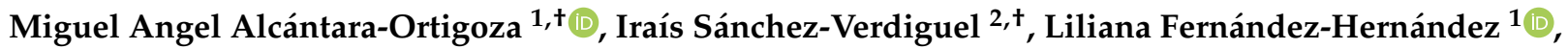 \\ Sergio Enríquez-Flores ${ }^{3}{ }^{\mathbb{D}}$, Aidy González-Núñez ${ }^{4}$, Nancy Leticia Hernández-Martínez ${ }^{1}$, Carmen $\mathrm{Sánchez}^{5}$ and \\ Ariadna González-del Angel 1,*(D)
}

\section{check for}

updates

Citation: Alcántara-Ortigoza, M.A.; Sánchez-Verdiguel, I.;

Fernández-Hernández, L.;

Enríquez-Flores, S.; González-Núñez,

A.; Hernández-Martínez, N.L.;

Sánchez, C.; González-del Angel, A. Further Evidence That Defects in

Main Thyroid Dysgenesis-Related Genes Are an Uncommon Etiology for Primary Congenital

Hypothyroidism in Mexican Patients: Report of Rare Variants in FOXE1, NKX2-5 and TSHR. Children 2021, 8 , 457. https://doi.org/10.3390 /children8060457

Academic Editor: Mikko Hallman

Received: 16 April 2021

Accepted: 27 May 2021

Published: 30 May 2021

Publisher's Note: MDPI stays neutral with regard to jurisdictional claims in published maps and institutional affiliations.

Copyright: (C) 2021 by the authors Licensee MDPI, Basel, Switzerland. This article is an open access article distributed under the terms and conditions of the Creative Commons Attribution (CC BY) license (https:/ / creativecommons.org/licenses/by/ $4.0 /)$.
1 Laboratorio de Biología Molecular, Subdirección de Investigación Médica, Instituto Nacional de Pediatría, Secretaría de Salud, Ciudad de Mexico CP 04530, Mexico; malcantaraortigoza@gmail.com (M.A.A.-O.); dralilianafernandez@gmail.com (L.F.-H.); yazzama@gmail.com (N.L.H.-M.)

2 Consulta Externa, Instituto Nacional de Pediatría, Secretaría de Salud, Programa de Maestría y Doctorado en Ciencias Médicas, Odontológicas y de la Salud, UNAM, Ciudad de Mexico CP 04530, Mexico; drairais@yahoo.com

3 Grupo de Investigación en Biomoléculas y Salud Infantil, Laboratorio de Errores Innatos del Metabolismo y Tamiz, Instituto Nacional de Pediatría, Ciudad de Mexico CP 04530, Mexico; sergioenriquez5@yahoo.com.mx

4 Hospital Regional Materno Infantil de Alta Especialidad de Nuevo León, Guadalupe CP 67140, Mexico; aidygn@gmail.com

5 Laboratorio de Seguimiento del Neurodesarrollo, Instituto Nacional de Pediatría,

Ciudad de Mexico CP 04530, Mexico; msanchez@correo.xoc.uam.mx

* Correspondence: ariadnagonzalezdelangel@gmail.com; Tel.: +52-55-1084-0900 (ext. 1306)

+ These authors contributed equally to this work.

Abstract: Mexico shows a high birth prevalence of congenital hypothyroidism $(\mathrm{CH})$ due to thyroid dysgenesis (TD). PAX8 defects underlie only $1 \%$ of these cases and NKX2-1 does not seem to be involved. Here, we analyzed other TD-related genes in 128 non-related Mexican patients (females $77.3 \%$; 6 months to 16.6 years) with non-syndromic $\mathrm{CH}-\mathrm{TD}$ diagnosis established by clinical evaluation, thyroid hormone serum profiling, and scintigraphy (74\%) or ultrasonography (26\%). We performed Sanger sequencing of FOXE1, NKX2-5, and TSHR and evaluated copy number variations (CNVs) in TSHR, FOXE1, PAX8, and NKX2-1 by multiplex ligation-dependent probe amplification. Odds ratios for TD risk were explored for FOXE1 polyalanine stretches [polyAla-rs71369530] in cases and controls $(\mathrm{N}=116)$. Five rare missense changes cataloged as benign (NKX2-5:p.(Ala119Ser)-rs137852684), of unknown significance (FOXE1:p.(Ala335Gly)-rs543372757; TSHR:p.(Asp118Asn)-rs1414102266), and likely pathogenic (FOXE1:p.(Gly124Arg)-rs774035532; TSHR:p.(Trp422Arg)-rs746029360) accounted for $1.5 \%(\mathrm{~N}=2 / 128)$ of clinically relevant genotypes (supported in part by protein modeling) in $\mathrm{CH}-\mathrm{TD}$. No CNVs were identified, nor did polyAla > 14 alanines in FOXE1 significantly protect against TD. The present and previously published data collectively show that small clinically relevant germline variants in PAX8, FOXE1, and TSHR are found in only a very small proportion (2.5\%) of isolated $\mathrm{CH}-\mathrm{TD}$ Mexican patients.

Keywords: congenital hypothyroidism; FOXE1; Mexican population; multiplex ligation-dependent probe amplification (MLPA); NKX2-1; NKX2-5; PAX8; polyalanine tract; protein modeling; thyroid dysgenesis; TSH receptor

\section{Introduction}

Congenital hypothyroidism $(\mathrm{CH})$ is considered the main preventable cause of intellectual disability at birth [1]. The incidence in non-Hispanic white populations is 1 in 
3533-4166 live newborns [1,2]. Overall, it is estimated that thyroid dysgenesis (TD, including athyrosis, ectopy, and hypoplasia) accounts for $71-87.3 \%$ of $\mathrm{CH}$ cases [3-5]. Great variability has been noted among different ethnicities, as exemplified by the predominance of autosomal recessive dyshormonogenetic forms in Chinese ( 70\%) [6] and Russian $(\sim 85 \%)$ [7] CH newborns. In the French population, $\sim 98 \%$ of $\mathrm{CH}$ due to TD (CH-TD) occurs as a sporadic event [4] that has an unknown etiology in $>90 \%$ of the cases [3]. However, the following observations suggest that there is a genetic component to $\mathrm{CH}-\mathrm{TD}$ : (a) The well-known high birth prevalence of $\mathrm{CH}$ in Hispanics (1:1600-1758) [1,2], including Mexicans, in whom an evident increase (1:1373) has been recently reported by newborn screening [8]; (b) the higher female:male sex ratio (2-3:1) mainly observed in Caucasian, Hispanic, and Mexican patients [1,2,5,8]; (c) the $>15$-fold estimated recurrence risk for first degree relatives of a sporadic $\mathrm{CH}-\mathrm{TD}$ patient [4]; (d) there are reported associations with extra-thyroidal congenital defects in Caucasian (8.2-9\%) [4], Brazilian (14.9\%) [9], and Mexican $(23 \%)$ [10] patients; (e) subtle functional (3.9-7.8\%) or developmental (1-10\%) thyroid abnormalities have been identified in first-degree relatives of $\mathrm{CH}$-TD patients [11,12]; and (f) the TD human phenotype has been replicated in mouse models null for a number of thyroidogenesis-related human orthologous genes (PAX8, FOXE1, NKX2-1, TSHR, etc.,) whose mono- or biallelic loss-of-function genotypes, even interacting in a polygenic model, may explain the etiology of $5-10 \%$ of $\mathrm{CH}-\mathrm{TD}$ patients [3].

The introduction of massively parallel or next-generation sequencing (NGS) has expanded the mutational spectrum of dyshormonogenesis and TD candidate genes for primary permanent $\mathrm{CH}$ in patients who were identified through newborn screening but lacked a formal thyroid imaging evaluation $[6,7,13]$. This approach has proven useful in documenting the wide allelic and locus heterogeneity underlying the thyroid hormone biosynthesis defects that predominate over TD in $\mathrm{CH}$ patients of some backgrounds, such as Chinese [6,13] and Russian [7] ones. To date, the five extensively studied TD candidate genes, FOXE1 (MIM*602617), NKX2-5 (MIM*600584), PAX8 (MIM*167415), TSHR (MIM+603372), and NKX2-1 (MIM*600635), appear to convincingly explain only $<10 \%$ of the CH-TD cases, even when assessed using a NGS approach $[3,7]$. At least six additional novel loci involved in the TD etiology have recently been described, but some are responsible for syndromic TD forms, and together the known genes still explain only a minority of patients [3]. In addition, assessing of pathogenic copy number variations (CNVs), as well as further explorations in distinct populations to French ones regarding to association of TD phenotype with FOXE1 polyalanine stretch (polyAla) genotypes [14], has not been evaluated by the employed bioinformatics pipelines in these recent NGS studies $[6,7,13]$. Evaluation of CNVs by multiplex ligation-dependent probe amplification (MLPA) identified whole-exon heterozygous deletions in PAX8, TSHR, and FOXE1 as being relevant pathogenic changes in $11 \%$ of $\mathrm{CH}$-TD Polish patients [15], but this has not been replicated in other populations $[7,16]$.

Mexico shows one of the highest and increasing worldwide $\mathrm{CH}$ birth prevalences [2,8], with the disease mostly attributable to TD ( 93\%) [17]. However, the etiology of the disease in this population remain largely elusive $[8,17]$. Two Sanger sequencing-based reports found that heterozygous loss-of-function PAX8 genotypes account for the etiology of $\sim 1 \%$ of Mexican CH-TD patients [18], and that clearly deleterious small nucleotide changes in NKX2-1 did not appear to be a factor in this population [19]. To gain a more comprehensive picture of the main TD-related genes in a Mexican population, we herein studied 128 unrelated Mexican patients at pediatric age, all bearing a confirmed clinical, biochemical, and thyroid imaging diagnosis of non-syndromic CH-TD. In them, Sanger sequencing was applied to characterize small nucleotide changes in NKX2-5, TSHR, and FOXE1 (including genotyping of the polyAla stretch proposed as a TD susceptibility polymorphic variant [14]) and MLPA to assess CNVs in TSHR, FOXE1, PAX8, and NKX2-1. As has been described for most populations [3], our results indicate that germline defects in the studied TD-related genes are a very uncommon or even a debatable genetic cause for the majority of Mexican 
CH-TD patients, and suggest that a single-gene model does not explain the high birth prevalence of this congenital disorder in Mexico.

\section{Materials and Methods}

\subsection{Population Study}

During 2013-2015, we recruited 128 non-related Mexican patients (99 females, 77.3\%) at pediatric age (6 months-16.6 years of age), all with a confirmed diagnosis of nonsyndromic, primary and permanent CH-TD, as evaluated by a pediatrician (I.S.-V.), neurodevelopmental specialist (C.S.), endocrinology pediatrician (A.G.-N.), and clinical geneticists (A.G.-d.A., L.F.-H.). Identification of $\mathrm{CH}$ relied on newborn screening in $89 \%$ $(\mathrm{N}=114 / 128)$ of participants. Further confirmation of $\mathrm{CH}-\mathrm{TD}$ was established by the presence of a thyroid hormone serum profile indicating hyperthyrotropinemia $(>10 \mu \mathrm{UI} / \mathrm{mL})$ and low total and free $\mathrm{T} 4(<4.5 \mathrm{mcg} / \mathrm{dL}$ and $<0.8 \mathrm{ng} / \mathrm{dL}$, respectively), as assessed in most of the patients $(74 \%, \mathrm{~N}=96 / 128)$ at ages 31-60 days after birth, as well as by the presence of an abnormal thyroid anatomy diagnosed in $74 \%(\mathrm{~N}=95 / 128)$ of patients by scintigraphy with radionuclide uptake of sodium pertechnetate $99 \mathrm{~m}$ (Tc99 $\mathrm{m}$ ) or by thyroid ultrasonography $(26 \%, \mathrm{~N}=33 / 128)$, which revealed $45.3 \%(\mathrm{~N}=58 / 128)$ instances of thyroid ectopy, $42.2 \%(\mathrm{~N}=54 / 128)$ of athyrosis, and $12.5 \%(\mathrm{~N}=16 / 128)$ of thyroid hypoplasia. Parental consanguinity was not referred to in any patient. In 14 families $(10.9 \%)$, different thyroid disorders $(\mathrm{CH}$, thyroid neoplasms, non-specified hypothyroidism, etc.,) were documented in second- or third-degree relatives and, in three cases, the mother endorsed primary $(\mathrm{N}=2)$ or unspecified hypothyroidism $(\mathrm{N}=1)$. Diverse central nervous system $(\mathrm{N}=4)$, ophthalmic $(\mathrm{N}=4)$, cardiovascular $(\mathrm{N}=3)$, genitourinary $(\mathrm{N}=2)$, orthopedic $(\mathrm{N}=6)$, and hematologic ( $\mathrm{N}=1$, factor XII deficiency) abnormalities were documented in $15.6 \%$ of patients, but no recognized syndromic form of $\mathrm{CH}-\mathrm{TD}$ was established during their clinical genetic evaluations. One familial case of neurofibromatosis type 1 (MIM\#162200) was identified in a patient (HC-222) and her mother. A normal Sanger sequencing result for the NKX2-1 gene was previously reported for 122 of the 128 patients included herein [19].

Written informed consent was obtained from parents of all included participants. This study was approved by the Research, Biosecurity and Ethics committees of the National Institute of Pediatrics, Mexico (Registries 083/2013 and 058/2019).

\subsection{Molecular Analysis}

2.2.1. Sanger Sequencing of NKX2-5, FOXE1, and TSHR

Genomic DNA samples were obtained from peripheral blood leukocytes by the saline precipitation method (Puregene kit; Gentra Systems, Minneapolis, MN, USA). Polymerase chain reaction (PCR) amplification and direct automated Sanger sequencing were applied to the two coding exons of NKX2-5 gene isoform 1 along the intron-exon boundaries (NM_004387.4 and NG_013340.1 RefSeqGene), the single coding exon of FOXE1 (NM_004473.4 and NG_011979.1 RefSeqGene) containing the polyAla stretch (rs71369530), and the 10 exons with their intron-exon boundaries of the TSHR gene isoform 1 precursor (NM_000369.5 and NG_009206.1 RefSeqGene). PCR oligonucleotides and sequencing conditions are presented in Table S1A.

Identified variants were classified according to the scoring proposed by the American College of Medical Genetics and Genomics and the Association for Molecular Pathology (ACMG/AMP) [20,21]. Unclassified, novel, or very-low-frequency missense changes were subjected to in silico analysis using the PolyPhen (http://genetics.bwh.harvard.edu/pph2, accessed on 8 March 2021), PROVEAN (http:// provean.jcvi.org/index.php, accessed on 8 March 2021), and Pmut (http://mmb.irbbarcelona.org/PMut, accessed on 8 March 2021) programs. They were also directly searched by allele-specific PCR assays (primer sequences and PCR conditions are in Table S1B) in 146 (292 alleles) healthy and unrelated Mexican individuals.

In order to explore a possible association between the polymorphic length of the polyAla tract of FOXE1 (rs71369530) and the CH-TD trait, we additionally genotyped the 
length of the polyAla stretches by Sanger sequencing in DNA samples of 116 (232 FOXE1 alleles) unrelated, healthy, and ethnically matched individuals. We used the 14-alanine allele and the 14/14 genotype as references, given that they showed the highest frequency among $\mathrm{CH}$-TD patients and healthy controls. We then compared the allelic frequencies for $<14$ or $>14$ alanines or genotypes including $\leq 14 / \leq 14$ or $\geq 14 / \geq 14$ alanines between patients and healthy controls. The odds ratio (OR) with $95 \%$ confidence interval (CI) was calculated by Fischer's exact test, with a statistical difference assumed at a significance level of 0.05 .

\subsubsection{MLPA Analysis of TSHR, FOXE1, PAX8, and NKX2-1}

To assess CNVs, each exon of these genes was evaluated by MLPA (SALSA ${ }^{\circledR}$ MLPA $^{\circledR}$ probemix P319-B1 Thyroid; MRC Holland, Amsterdam, The Netherlands) according to the manufacturer's instructions. The kit do not included probes to analyze CNVs in the NKX2-5 gene. The obtained gene dosages were evaluated using the Coffalyser.Net Software (MRC Holland, Amsterdam, The Netherlands).

\subsection{Structural Modeling of the Human Forkhead Box E1 (FOXE1) and Thyrotropin Receptor Isoform 1 Precursor (TSHR) Proteins}

Through protein in silico modeling, we further assessed the potential deleterious effects of the identified missense variants cataloged as being of unknown significance (VUS) or likely pathogenic, and lacking evidence by functional assays. To construct protein models, we used the amino acid reference sequences NP_004464.2 and NP_000360.2 for human forkhead box E1 (FOXE1) and thyrotropin receptor isoform 1 precursor (TSH receptor), respectively. Only the sequence spanning amino acids 46 to 156 was considered when we created a model for FOXE1. The 3D model of this amino acid sequence was obtained using the I-TASSER server (http: / / zhanglab.ccmb.med.umich.edu/I-TASSER, accessed on 8 April 2021) [22], which is based in the Local MEta-Threading-Server (LOMETS) [23] and looks for structural templates similar to the query amino acid sequence deposited in the Protein Data Bank (PDB); these are then assembled as template fragments (threaded) into a complete protein model. To define the possible implications of the rare missense variants in FOXE1, we used the crystallographic structure of interleukin 1 enhancer binding factor in complex with DNA [24]. This structure showed high structural similarity with the FOXE1 model (RMSD for all the C $\alpha$ atoms $=0.619 \AA$ ). Once the structures were aligned, the crystallographic coordinates of the interleukin 1 protein were deleted, and the FOXE1 and DNA structures were analyzed. We were unable to model the C-terminal domain of FOXE1, where p.(Ala335Gly) is located, due to the lack of crystallographic data.

For TSH receptor modeling, we used a fragment of crystallographic structure deposited in the PDB (code: 2xwt, aminoacyl residues 24 to 257) [25]. The rest of the amino acid sequence (residues 258 to 764 ) was then applied to construct a 3D model using the ITASSER server and following the above described protocol.

Once we obtained the best models for both proteins, we subjected them to energy minimization with the Molecular Modeling System UCSF Chimera software [26]. The new coordinates were manually inspected, evaluated for their geometric quality, and validated with MOLPROBITY (http:/ / molprobity.biochem.duke.edu, accessed on 8 April 2021) [27]. The electrostatic potential of the TSH receptor model was determined with the PBEQ Solver server (http:/ / www.charmm-gui.org/?doc=input/pbeqsolver\&step=0, accessed on 8 April 2021) [28]. The aminoacyl sequence of the transmembrane region of the TSH receptor model was calculated with PROTTER (https:/ / wlab.ethz.ch/protter/start, accessed on 8 April 2021) [29], and later embedded into the membrane structure generated by the VMD software [30].

Finally, in silico mutagenesis for missense variants of the FOXE1 and TSHR models was performed using the molecular graphics system, PyMOL (Molecular Graphics System, v.2.2.0 Schrödinger, LLC). 


\section{Results}

Sanger sequencing of the analyzed genes did not reveal any patently pathogenic variant in the $128 \mathrm{CH}$-TD patients analyzed. However, five rare and single-nucleotide missense changes cataloged as benign (NKX2-5, $\mathrm{N}=1$ ), VUS (FOXE1 and TSHR, $\mathrm{N}=1$ each), and likely pathogenic (FOXE1 and TSHR, $\mathrm{N}=1$ each) were identified in CH-TD patients (Table 1) and were absent from healthy controls. Genotypes and clinical and thyroid phenotypes documented in these four $\mathrm{CH}$-TD patients, who did not have any other extra-thyroidal congenital abnormality, are summarized in Table 1 along with other relevant data. Similarly, no CNV was identified by MLPA of the analyzed genes. The main findings of our protein modeling of p.(Gly124Arg) in FOXE1, p.(Asp118Asn) and p.(Trp422Arg) in TSHR are summarized in Figures 1 and 2, respectively.

Table 1. Genotypic and clinically relevant data identified by Sanger sequencing of NKX2-5, FOXE1, and TSHR genes among 128 Mexican unrelated $\mathrm{CH}-\mathrm{TD}$ patients.

\begin{tabular}{|c|c|c|c|c|}
\hline $\begin{array}{l}\text { Patient ID } \\
\text { (Gender) }\end{array}$ & Genotype & $\begin{array}{l}\text { ACMG/AMP }{ }^{1} \text { Criteria } \\
\text { and Variant } \\
\text { Classification GnomAD } \\
\text { Allele Frequencies }^{2}\end{array}$ & $\begin{array}{l}\text { Thyroid and Clinical } \\
\text { Phenotype }\end{array}$ & Relevant Familial History \\
\hline $\begin{array}{l}\text { HC-266 } \\
\text { (female) }\end{array}$ & $\begin{array}{c}\text { Homozygous NM_004473.3 } \\
\text { (FOXE1):c.370G>C or } \\
\text { p.(Gly124Arg) [rs774035532] at } \\
\text { forkhead domain. } \\
\text { Homozygous for } 16 \text { alanine } \\
\text { polyAla tract. }\end{array}$ & $\begin{array}{c}\text { PM1, PM2, PP2, PP3. } \\
\text { Likely pathogenic (V). } \\
0.000016\end{array}$ & $\begin{array}{l}\text { Thyroid hypoplasia } \\
\text { (scintigraphy) without other } \\
\text { birth defects or clinical data } \\
\text { suggestive of } \\
\text { Bamforth-Lazarus syndrome } \\
\text { (MIM\#241850). }\end{array}$ & $\begin{array}{l}\text { No familial history of } \mathrm{CH} . \\
\text { Healthy apparently } \\
\text { non-consanguineous parents } \\
\text { with normal thyroid profiles. } \\
\text { Heterozygous for } \\
\text { p.(Gly124Arg) and 14/16 } \\
\text { alanine polyAla FOXE1 } \\
\text { genotypes. }\end{array}$ \\
\hline $\begin{array}{l}\text { HC-215 } \\
\text { (female) }\end{array}$ & $\begin{array}{c}\text { Heterozygous NM_004473.3 } \\
\text { (FOXE1):c.1004C>G or } \\
\text { p.(Ala335Gly) [rs543372757]. } \\
\text { Heterozygous for 14/16 alanine } \\
\text { tract. }\end{array}$ & $\begin{array}{l}\text { PM2, PP2. } \\
\text { Variant of unknown } \\
\text { significance. } \\
0.0000076\end{array}$ & $\begin{array}{l}\text { Thyroid ectopy (scintigraphy) } \\
\text { without other birth defects. }\end{array}$ & $\begin{array}{c}\text { No familial history of } \mathrm{CH} \text {. } \\
\text { Healthy non-consanguineous } \\
\text { parents with normal thyroid } \\
\text { profile. } \\
\text { Mother heterozygous for } \\
\text { c. } 1004 \mathrm{C}>\mathrm{G} \text { or p.(Ala335Gly). }\end{array}$ \\
\hline $\begin{array}{l}\text { HC-321 } \\
\text { (male) }\end{array}$ & $\begin{array}{l}\text { Heterozygous NM_004387.3 } \\
\quad(\text { NKX2-5):c.355G>T or } \\
\text { p.(Ala119Ser) [rs137852684]. }\end{array}$ & $\begin{array}{c}\text { PM2, PP2, BP6, BS2, BS4. } \\
\text { Benign (II). } \\
0.00097\end{array}$ & $\begin{array}{l}\text { Thyroid ectopy (scintigraphy) } \\
\text { without other birth defect. }\end{array}$ & $\begin{array}{c}\text { No familial history of } \mathrm{CH} \text { or } \\
\text { congenital heart disease. } \\
\text { Healthy non-consanguineous } \\
\text { parents with normal thyroid } \\
\text { profile. } \\
\text { Father heterozygous for } \\
\text { c.355G }>\text { T or p.(Ala119Ser) } \\
\text { without any clinical data } \\
\text { suggestive of heart disease. }\end{array}$ \\
\hline $\begin{array}{l}\mathrm{HC}-324 \\
\text { (female) }\end{array}$ & $\begin{array}{c}\text { Compound } \\
\text { heterozygous } \\
\text { NM_000369.2(TSHR) } \\
\text { c.[352G }>\text { A ];[1264T }>\text { C] } \\
\text { or p.[Asp118Asn];[Trp422Arg] } \\
\text { (rs1414102266 and rs746029360). }\end{array}$ & $\begin{array}{c}\text { p.(Asp118Asn): } \\
\text { PM2, PP2, BP4. } \\
\text { Variant of unknown } \\
\text { significance. } \\
\text { 0.0000039 } \\
\text { p.(Trp422Arg): PM1, PM2, } \\
\text { PP2, PP3. } \\
\text { Likely pathogenic (V). } \\
0.000015\end{array}$ & $\begin{array}{c}\text { Thyroid agenesis } \\
\text { (ultrasonography); serum } \\
\text { thyroglobulin levels not } \\
\text { available. }\end{array}$ & $\begin{array}{l}\text { No familial history of } \mathrm{CH} \text {. } \\
\text { Healthy non-consanguineous } \\
\text { parents not available for } \\
\text { thyroid profile evaluation or } \\
\text { TSHR genotyping. }\end{array}$ \\
\hline
\end{tabular}

${ }^{1}$ Accordingly to the available online tool https:/ / www.medschool.umaryland.edu/genetic_variant_interpretation_tool1.html/ (accessed on 8 March 2021) [21], which is based on the American College of Medical Genetics and Genomics and the Association for Molecular Pathology standards and guidelines for the interpretation of sequence variants [20]. ${ }^{2}$ Worldwide allelic frequencies reported at gnomAD database v2.1.1 (https:/ / gnomad.broadinstitute.org, accessed on 27 May 2021). 


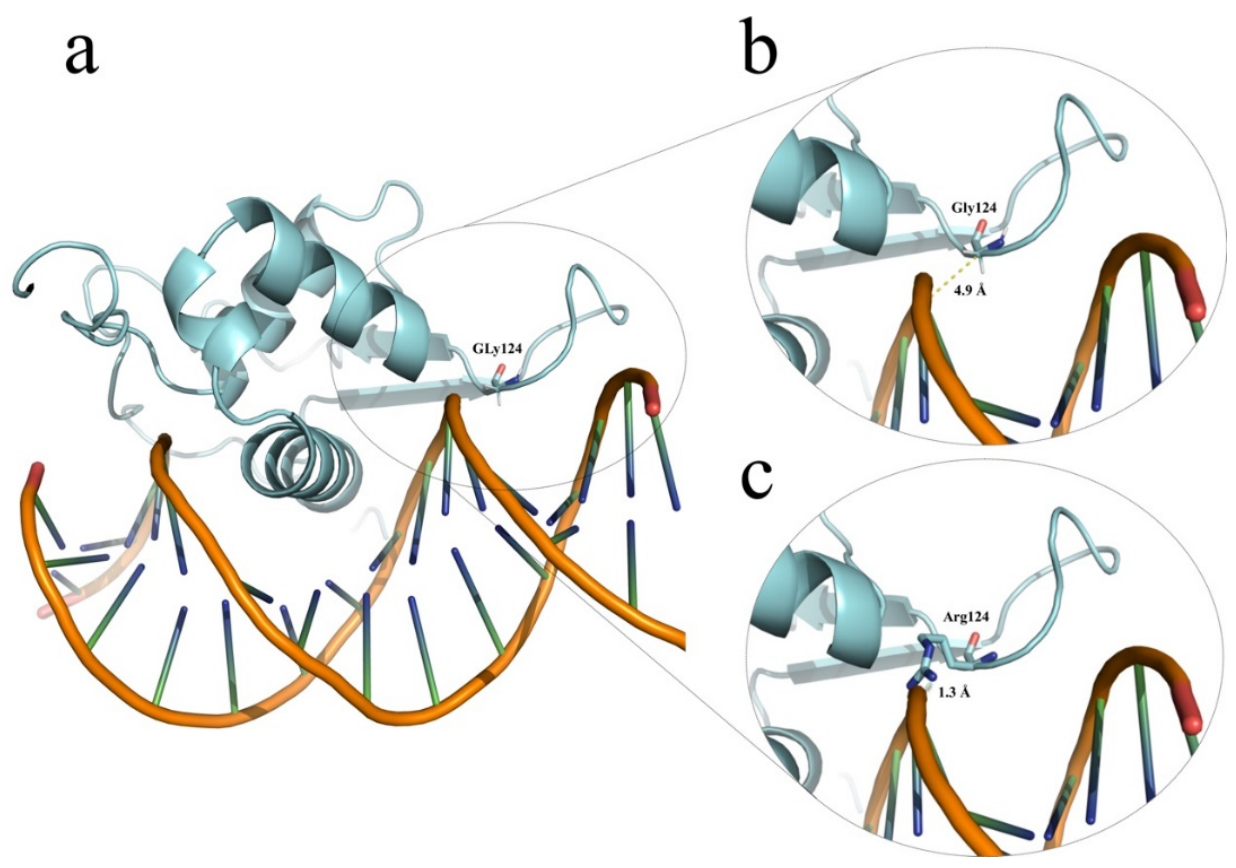

Figure 1. Partial FOXE1 modeling. (a) Schematic representations of our in silico modeling of FOXE1 in contact with DNA, as obtained with the PyMOL software. (b) The close-up shows a distance of $4.9 \AA$ separating Gly124 from the minor groove of DNA. (c) In contrast, the model for the protein with a Gly124 to Arg124 substitution identified in HC-266 shows only $1.3 \AA$ A separating Arg124 from DNA; this leads to clash contacts, which could destabilize or alter the DNA-binding affinity of the mutant FOXE1. The 3D model was structurally aligned with the crystallographic structure of interleukin 1 (PDB code: 2C6Y).

Predominance of 14 alanines in the polyAla FOXE1 tract and homozygosity for this allele (14/14 alanines) was noted both in patients ( 0.86 and $75 \%$, respectively) and healthy controls (0.87 and $78.4 \%$, respectively), while the 16 alanine tract and $14 / 16$ polyAla heterozygosity were the second most common allele and genotype identified among patients (0.097 and $17.9 \%$, respectively) and controls ( 0.11 and $17.2 \%$, respectively). Rare single alleles containing 10 and 17 alanines were identified in the heterozygous state in only two CH-TD patients (bearing 10/14 and 14/17 polyAla genotypes).

Fischer's exact test did not reveal any significant statistical difference in the distributions of the $<14$ versus $>14$ alanine alleles or the $\leq 14 / \leq 14$ or $\geq 14 / \geq 14$ genotypes between patients and healthy controls. The genotypic data and statistical associations regarding the polyAla FOXE1 polymorphic tract are presented in Table 2.

Table 2. Fisher's exact test results for FOXE1 polyAla alleles and genotypes between CH-TD and healthy controls.

\begin{tabular}{|c|c|c|c|c|c|c|}
\hline PolyAla Allele & $\begin{array}{c}\text { CH-TD Alleles } \\
(\mathrm{N}=256)\end{array}$ & Allelic Frequencies & $\begin{array}{l}\text { Healthy Control } \\
\text { Alleles }(\mathrm{N}=\mathbf{2 3 2})\end{array}$ & $\begin{array}{c}\text { Allelic } \\
\text { Frequencies }\end{array}$ & OR $(95 \% \mathrm{CI})$ & $p$-Value \\
\hline$<14$ alanines & 8 & 0.03125 & 2 & 0.0172 & $3.67(0.77-17.5)$ & 0.110 \\
\hline 14 alanines (reference) & 222 & 0.8671 & 204 & 0.8793 & & \\
\hline$>14$ alanines & 26 & 0.1015 & 26 & 0.1120 & $0.91(0.51-1.63)$ & 0.883 \\
\hline PolyAla genotype & $\begin{array}{l}\text { CH-TD patients } \\
(\mathrm{N}=128)\end{array}$ & Frequency (\%) & $\begin{array}{l}\text { Healthy controls } \\
\quad(\mathrm{N}=116)\end{array}$ & Frequency & OR $(95 \% \mathrm{CI})$ & $p$-Value \\
\hline$\leq 14 / \leq 14$ alanines & 7 & 5.5 & 2 & 1.7 & $\begin{array}{c}3.31 \\
(0.67-16.39)\end{array}$ & 0.174 \\
\hline $\begin{array}{l}\text { 14/14 alanines } \\
\text { (reference) }\end{array}$ & 96 & 75 & 91 & 78.5 & & \\
\hline$\geq 14 / \geq 14$ alanines & 25 & 19.5 & 23 & 19.8 & $0.91(0.54-1.94)$ & 1.0 \\
\hline
\end{tabular}

Abbreviations: CI: confidence interval; CH-TD: congenital hypothyroidism by thyroid dysgenesis; OR: odds ratio. 


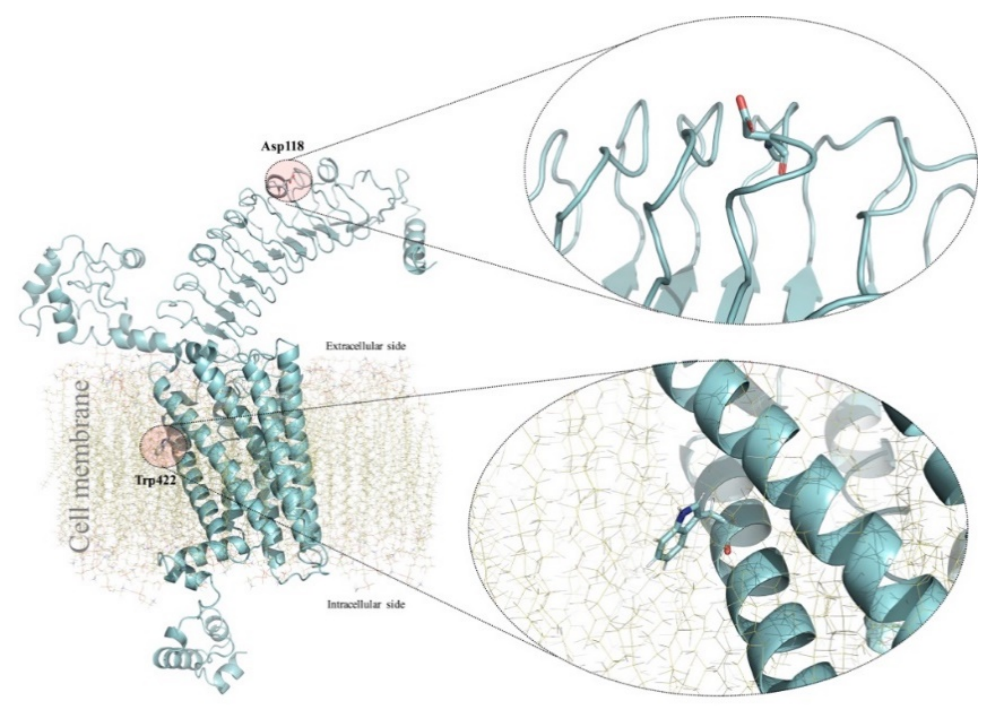

(a)

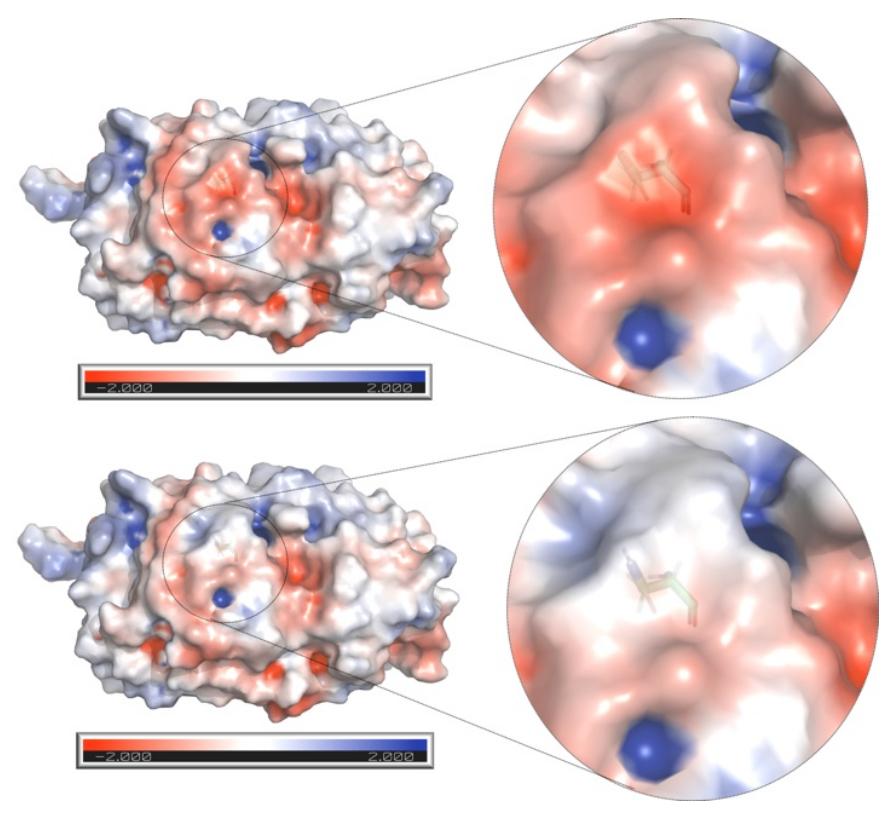

(b)

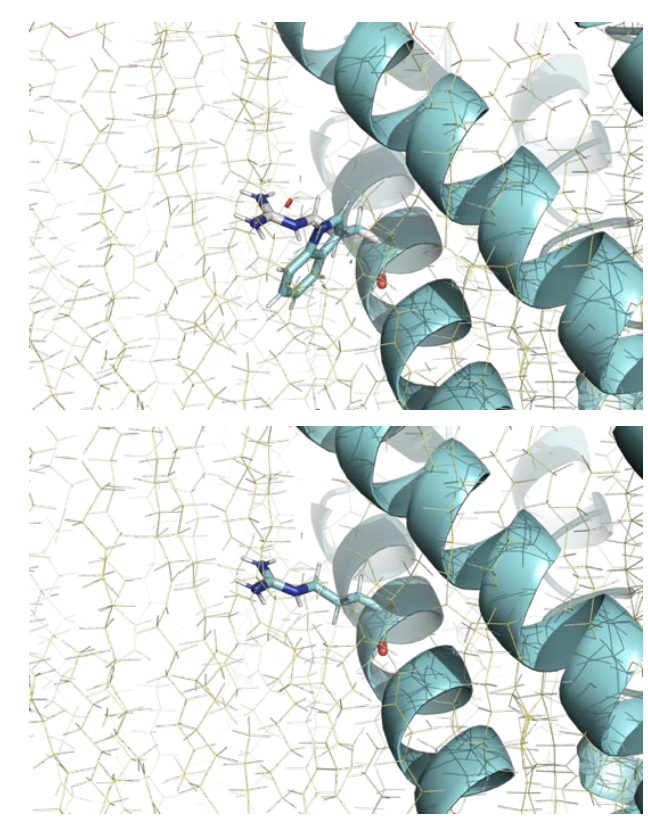

(c)

Figure 2. TSH receptor modeling. (a) Schematic representations of the complete in silico model of TSH receptor obtained with the PyMOL software, indicating the positions of Asp118 and Trp422 (including a close-up, right) involved in the substitutions identified in HC-324. (b) Electrostatic potential surface modeling of the convex side of the crystallographic structure (PDB code: 2XWT) of the wild-type (upper) and mutant (lower) proteins, showing that the Asp-to-Asn substitution at residue 118 induces a change from a negative (zoomed at the top) to a positive (zoomed at the bottom) electrostatic potential surface. (c) Close-up of position 422 in the first transmembrane domain of TSH receptor with modeling of superimposed Trp and Arg amino acids (top). The substituted amino acid residue (bottom) reveals close contact with the cell membrane.

\section{Discussion}

Hispanics [1,2], including Mexicans [8], have the highest worldwide birth prevalence of $\mathrm{CH}$. In contrast to the information available in the literature for Caucasian and Asian $\mathrm{CH}$ patients $[3,6,7,13,16]$, relatively little is known about the participation of genetic factors in the etiology of $\mathrm{CH}-\mathrm{TD}$ in Latin-American populations. To date, limited publications 
are available for Brazilian [31,32] and Mexican [18,19] populations. Given the predominance of TD ( 93\%) in the etiology of primary permanent $\mathrm{CH}$ in Mexicans [17], the aim of this work was to examine whether germline small-nucleotide (NKX2-5, FOXE1, and TSHR) and CNV-type (FOXE1, PAX8, NKX2-1, PAX8, and TSHR) changes in TD-related genes play an etiological role in some Mexican $\mathrm{CH}$ patients lacking clinical suspicion of a syndromic form and with a confirmed TD imaging-based diagnosis. Our results showed that $\sim 1.5 \%$ of studied CH-TD patients $(\mathrm{N}=2 / 128)$ presented relevant FOXE1 $(\mathrm{HC}-266)$ and TSHR (HC-324) genotypes involving single-nucleotide, missense, and likely pathogenic classified variants (Table 1 ). We failed to identify any CNV-type change. Our results add to previous findings that $1 \%$ of $\mathrm{CH}-\mathrm{TD}$ Mexican patients could be attributed to PAX8 missense defects [18], and there was no discernible participation of small-nucleotide NKX21 pathogenic changes [19]. Collectively, these data obtained in $\geq 100$ Mexican patients suggest that germline small-nucleotide defects in the main TD-related genes, PAX8 [18], NKX2-1 [19], FOXE1, NKX2-5, and TSHR (this work), could explain 2.5\% of the isolated $\mathrm{CH}$-TD cases in Mexico, without any identified etiologic role for CNVs in PAX8, NKX2-1, FOXE1, or TSHR (NKX2-5 was not included in the employed MLPA kit). Although this explains only a small proportion of cases, it is higher than that documented in 90 Brazilian CH-TD patients, where PAX8, NKX2-5, TSHR, and HES1 (MIM * 139605) did not reveal any pathogenic or VUS change [31,32], and seems quite similar to the rate obtained in Japanese $\mathrm{CH}$ patients $(2.0 \%, \mathrm{~N}=2 / 102)$, at least $50 \%$ of whom carried a confirmed TD phenotype [16]. Future genetic studies for other novel TD candidate loci (e.g., GLIS3, JAG1, CDCA8, NTN1, TUBB1, and/or THRB) [3] could be warranted in our population.

At least in the clinical setting, the European Society for Paediatric Endocrinology Consensus Guidelines on Screening, Diagnosis, and Management of $\mathrm{CH}$ recommends that molecular genetic study should be preceded by a careful clinical evaluation of the $\mathrm{CH}$ patients along with delineation of the thyroid phenotype [33]. However, this clinical aspect was not considered in recent genetic studies involving a larger number of Russian [7] and Chinese [6,13] samples. This precluded the authors from offering an updated and reliable proportion of molecular defects in TD-related genes and led to the predominant identification of dyshormonogenesis-related genotypes. In fact, we consider that the lower frequency of extra-thyroid abnormalities identified in the present study, compared to a previous report in Mexican $\mathrm{CH}$ patients (15.6 vs. $23 \%$, respectively) [10], reflects that we performed clinical evaluation to exclude the known TD syndromic forms. The inclusion of such cases may have biased the accurate estimation of mutational spectrum underlying the most common isolated TD forms in both Caucasian [4,5] and Mexican [17] CH cases. Such a bias could be exemplified by the recurrent identification of brain-lung-thyroid syndrome (MIM\#610978) in other studies [34,35].

CNV-type changes in TD-related genes have not been explored in Latin American $\mathrm{CH}$ populations $[18,19,31,32]$. In a small sample of Polish CH-TD patients directly subjected to MLPA, whole-exon heterozygous deletions in PAX8, TSHR, and FOXE1 genes surprisingly comprised $11 \%(N=5 / 45)$ of the underlying TD pathogenic genotypes [15]. The two monoallelic PAX8 gene deletions identified in the Polish study agreed with the idea that a haploinsufficiency mechanism correlates with the reported thyroid ectopy and athyrosis phenotypes [3]. However, the authors found it difficult to explain the TD phenotype in the remaining three patients bearing monoallelic TSHR and FOXE1 deletions [15], especially as they did not identify a second pathogenic allele (i.e., by whole-gene sequencing) in these patients. The absence of these gene rearrangements in our larger sample of $\mathrm{CH}$-TD Mexican patients agree with the data obtained from Japanese (PAX8, NKX2-1, and FOXE1) [16] and Russian (1/243 CH patients with PAX8 heterozygous deletion, no deletions in TPO, FOXE1, NKX2-1, or TSHR) [7] CH patients. Thus, with the exception of the Polish experience, CNVs seem to represent an uncommon pathogenic mechanism associated with TD in several $\mathrm{CH}$ populations.

A recent analysis of pooled literature supported the idea that heterozygous missense variants located at PAX8, TSHR, FOXE1, and NKX2-5 could increase the risk for developing 
permanent $\mathrm{CH}(\mathrm{OR}=37.38,95 \%$ CI 5.04-277.21) [36]. In our study, we identified a total of five rare missense single-nucleotide changes in FOXE1 $(\mathrm{N}=2$, homozygous and heterozygous genotypes), NKX2-5 ( $\mathrm{N}=1$, heterozygous genotype), and TSHR $(\mathrm{N}=2$, compound heterozygous genotype); of them, only two were cataloged as "likely pathogenic" variants (Table 1).

Most alleles conditioning the Bamforth-Lazarus syndrome are missense changes that impair the DNA-binding activity of the FOXE1 forkhead domain (amino acid positions 53 to 141) [37]. The Gly124 position is located just inside this domain and shows high phylogenetic conservation from human to zebrafish. The non-conservative amino acid substitution identified in HC-266 changes a small hydrophobic amino acid (glycine) to a positively charged and larger residue (arginine). Our protein modeling indicated that Gly124 is in close contact with DNA, and its drastic substitution with an arginine causes clash contacts (Figure 1), leading to a possible destabilization of the FOXE1 DNA-binding site. This modeling correlates with the in silico predictions made by the PolyPhen, PROVEAN, and Pmut programs, which unanimously predicted the p.(Gly124Arg) FOXE1 variant as deleterious with high confidence scores. To date, the p.(Gly124Arg) FOXE1 allele (rs774035532) exhibits a very low worldwide allelic frequency $(0.0016 \%)$ and has been identified exclusively in four heterozygous Latin American individuals according to gnomAD database (https:/ /gnomad.broadinstitute.org/variant/9-100616566-G-C, accessed on 27 May 2021). Although there have been a few reported cases of Bamforth-Lazarus syndrome, a wide variation in clinical expressivity has been noted. For example, not all described patients have choanal atresia or epiglottic bifidity, and a minority shows a thyroid hypoplasia instead of athyrosis [37], as seen in our patient HC-266. Attempts to correlate this variable clinical expressivity with the residual functional activity of mutant FOXE1 protein have not been conclusive [37], and functional studies based on gel mobility-shift and transfection assays are needed to corroborate if p.(Gly124Arg) along with a 16 alanine polyAla tract represents a hypomorphic FOXE1 allele that retains considerable residual function to prevent the full development of Bamforth-Lazarus syndrome and only leave $\mathrm{CH}$-TD as the phenotypic manifestation. To the best of our knowledge, our patient HC-266 could represent the first case of a non-syndromic CH-TD diagnosed by newborn screening and bearing a likely pathogenic biallelic FOXE1 genotype, which expands the phenotypic spectrum for FOXE1related disorders. On the other hand, it is generally assumed that the heterozygous parents of Bamforth-Lazarus syndrome patients are healthy and euthyroid [37], as was documented in the parents of HC-266. Unfortunately, we lacked information on the thyroid morphology in these obligate carriers and thyroid image evaluations could not be performed to discard any asymptomatic congenital thyroid defect. In addition to the 16/16 polyAla genotype in HC-266, we noted homozygosity at the rs201181824, rs139551528, rs371516340, and rs3021526 sites (data not shown). This could suggest an identity-by-descent for the 9q22.33 region, potentially reflecting endogamy or consanguinity of the parents (although such antecedents were denied), as has been described for most Bamforth-Lazarus syndrome families [37].

The asymptomatic carrier status for proven pathogenic FOXE1 alleles makes it difficult to propose any etiological role for heterozygous VUS in the development of CH-TD. Such heterozygosity was seen for the p.(Pro8Arg) and p.(Leu112Phe) variants recently identified in Chinese $\mathrm{CH}$ patients and their healthy parents [13], and the p.(Ala335Gly) [rs543372757] herein reported for HC-215 and her euthyroid mother (Table 1). The p.(Ala335Gly) is an extremely infrequent allele worldwide $(0.00076 \%)$; to date, it has been identified only in the heterozygous state (2/121660 alleles) in European (Non-Finnish)-descent populations (https: / / gnomad.broadinstitute.org/variant/9-100617200-C-G, accessed on 27 May 2021). The Ala335 position does not show a high degree of phylogenetic conservation, and it is located at the C-terminus of FOXE1, which is devoid of critical domains or known pathogenic variants. The p.(Ala335Gly) variant involves a conservative change, as alanine and glycine are small and hydrophobic residues; however, the in silico predictions of its effects were contradictory, ranging from tolerated to probable damaging. Unfortunately, 
we were unable to perform in silico modeling for the C-terminal domain of FOXE1, and thus could not use this information to consider its possible deleterious effects. Thus, future functional analysis and assessment of its cosegregation with the CH-TD trait in the homozygous state in other families are needed to determine the benignity or pathogenicity of this variant.

The knockout Nkx2-5/- mouse model develops thyroid bud hypoplasia [38], a feature that encouraged the study of its human homologue in CH-TD patients [3,38], especially those with associated congenital heart defects (CHD) [39]. However, although NKX2-5 has been extensively studied among different $\mathrm{CH}$ populations, including Chinese [13], Japanese [16], Brazilian [31,32], Czech [39], Dutch [40], and Iranian [41] patients, no fully penetrant pathogenic genotype has been found to condition CH-TD [40], with or without CHD [38-40], nor is TD a characteristic feature of patients with CHD attributable to NKX2-5 defects [40]. We did not herein carry out CNV evaluation for NKX2-5, although it is currently thought that genetic testing of NKX2-5 is not necessarily indicated in TD [3,40]. However, some studies $[38,40,41]$ commonly reported two likely benign missense changes: p.(Arg25Cys) [rs28936670] and the herein-identified (HC-321) p.(Ala119Ser) [rs137852684]. The latter change is located upstream from the homeobox NKX2-5 domain (amino acid positions 145 to 194); it is an uncommon allele (0.001340) among the European populations, but homozygous individuals have been identified in South Asian populations (https: / / gnomad.broadinstitute.org/variant/5-172660192-C-A, accessed on 27 May 2021). This, coupled with the recent functional in vitro evidence, the lack of cosegregation with CHD, the absence of TD in heterozygous individuals, and the healthy and euthyroid status observed in the heterozygous father of HC-321, collectively support a benign feature for p.(Ala119Ser) [40]. However, it still remains to be determined if these and other documented monoallelic NKX2-5 VUS in CH patients, i.e., p.(Ser139Asn) [6], p.(Arg143Gln) [35], p.(Pro211Leu) [34], and p.(Asp226Asn) [7], could play roles as genetic susceptibility factors, even in a digenic or polygenic model [3,42].

TSHR-related disorders display a broad clinical spectrum due to wide allelic heterogeneity. Monoallelic or biallelic loss-of-function variants of TSHR condition partial or complete TSH resistance, respectively. The first is generally manifested as mild postnatal hyperthyrotropinemia (hyperTSH) associated with an apparently euthyroid state accomplished by a normal-sized and orthotopic gland; the second is generally characterized as severe non-autoimmune $\mathrm{CH}$ due to thyroid hypoplasia [43]. This complete TSH resistance leads to $\mathrm{CH}$ identified by TSH-based newborn screening [43], as occurred with HC-324: This patient was diagnosed at 1 month of age through a marked elevation of serum TSH (>150 $\mu \mathrm{UI} /$, reference value: 0.4-4-0 $\mu \mathrm{UI} / \mathrm{mL})$ along with severe hypothyroidism (total T3: $10 \mathrm{ng} / \mathrm{dL}$, ref. value: $72-170 \mathrm{ng} / \mathrm{dL}$; free T3: $0.01 \mathrm{pg} / \mathrm{mL}$, ref. value: 1.8-6.0 pg/mL; total T4: $0.7 \mathrm{mcg} / \mathrm{dL}$, ref. value: $4.5-12.5 \mathrm{mcg} / \mathrm{dL}$; free T4: $0.4 \mathrm{ng} / \mathrm{dL}$, ref. value: $0.8-1.9 \mathrm{ng} / \mathrm{mL}$ ). Thus, it seems plausible to consider the compound heterozygous p.[Asp118Asn];[Trp422Arg] as a potential loss-of-function biallelic TSHR genotype. These missense variants are not currently described as being responsible for TSH resistance in ClinVar (https: / / www.ncbi.nlm.nih.gov / clinvar, accessed on 8 March 2021), Human Gene Mutation Database (HGMD ${ }^{\circledR}$, http:/ / www.hgmd.cf.ac.uk/ac/index.php, accessed on 8 March 2021), LOVD 3.0 (https: / / databases.lovd.nl/shared/genes/TSHR, accessed on 8 March 2021), or TSH Receptor Mutation Database (https: / / tsh-receptor-mutationdatabase.org/list.html, accessed on 8 March 2021), and to the best of our knowledge, they have not been previously reported as being responsible for any TSHR-related disorder. The p.(Asp118Asn) and p.(Trp422Arg) variants display extremely low worldwide allelic frequencies (0.00039\%: https: / / gnomad.broadinstitute.org/variant/14-81554332-G-A and 0.0015\%: https: / gnomad.broadinstitute.org/variant/14-81609666-T-C, respectively; accessed on 27 May 2021) and they have been identified exclusively in heterozygous Latin American individuals. The crystallographic structure (ranging from amino acids 24 to 257) deposited in PDB (code: 2XWT) and our 3D protein model (Figure 2) indicate that p.(Asp118Asn) is located in the third leucine-rich-repeat (LRR, amino acids 66 to 221) inside 
the large N-terminal extracellular domain of the TSH receptor, where several pathogenic missense changes have been described as altering ligand-binding capacity and/or reducing the receptor's cell surface expression [43]. It is well-known that $\mathrm{G}$ protein-coupled receptors, like TSH receptor, can exist as dimers and higher-order complexes [44], and the substitution of tyrosine 116 (located at $3.9 \AA$ from Asp118) to serine was reported to totally abrogate the formation of multimers [45]. Since Asp118 is found on the same convex surface of LRR region 1, it seems plausible that this residue could participate in the formation of TSH receptor multimers. Additionally, the p.(Asp118Asn) variant involves the substitution of a negatively charged surface amino acid for a positively charged residue and is predicted to alter the surface electrostatic potential (Figure 2), which largely determines the proper electrostatic interactions of TSH receptor with its ligand and/or blocking antibodies [25,46].

The p.(Trp422Arg) variant is a non-conservative substitution that changes a polar, hydrophobic (tryptophan) residue to a positively charged (arginine) one; it affects a phylogenetically invariable position and could disturb the hydrophobic milieu of the first transmembrane domain (TM helix 1, amino acids 416 to 442, Figure 2), where substitutions close to Trp422 have been reported to interfere with phospholipase C-activating G-protein coupled receptor signaling [43,47]. Regardless of the classification of these variants according to ACMG/AMP criteria (Table 1) and protein modeling predictions (Figure 2), further functional studies performed in vitro will be needed to determine if they impair some of the described cellular mechanisms governed by TSH receptor.

Profound thyroid hypoplasia without thyroid Tc $99 \mathrm{~m}$ uptake is characteristic of complete TSH resistance [43], which contrasts with the athyrosis phenotype documented in HC-324 by ultrasonography at 18 months of age. Unfortunately, the lack of serum thyroglobulin in HC-324 does not allow to disclose the absence of thyroid tissue, and several factors (i.e., younger age) could interfere with the accurate delineation of a thyroid phenotype by ultrasonography, where it has been estimated that up to $18 \%$ of the cases could be misdiagnosed mainly as athyrosis [48].

To further support the pathogenicity of the TSHR variants identified in HC-324, TSHR genotyping and complete thyroid profiling should be performed in both parents to assure their obligate heterozygous status, and assessment for possible partial and non-autoimmune TSH resistance [43] should be performed. Even if we assume that the identified p.[Asp118Asn];[Trp422Arg] variants represent a clinically relevant TSHR genotype, these defects seem to be a very uncommon genetic etiological factor for $\mathrm{CH}-\mathrm{TD}$ in our population $(<1 \%, \mathrm{~N}=1 / 128)$. This contrasts with the situation in various other populations, where biallelic or monoallelic TSHR genotypes are estimated to account for around $4-9 \%$ of $\mathrm{CH}$ cases [43]. However, it should be noted that the highest reported proportions have been documented in small samples of Italian $(\sim 7 \%, \mathrm{~N}=1 / 14)$ [49], Macedonian-Albanian $(14 \%, \mathrm{~N}=2 / 14)$ [50], and multiethnic $\mathrm{CH}$ patients that were enriched for familial forms $(2.9 \%, \mathrm{~N}=1 / 34$ families) [51] showing an in situ thyroid gland. This contrasts with our study population, as most of the included patients $(87.5 \%)$ presented ectopy and athyrosis.

Finally, we explored whether the polyAla FOXE1 tract was associated with the TD trait in our population. In a previous case-control study and transmission disequilibrium test in French Caucasians, the 16 alanine allele (either $14 / 16$ heterozygous or 16/16 homozygous status; allele dose effect) was identified as a protective TD factor $(0.39,95 \% \mathrm{CI}=0.22-0.68$, $p=0.0005$ ) [14]. This contrasted with a TD risk of OR 3.02 for the 14/16 genotype observed in Sicilian primary permanent $\mathrm{CH}$ patients [52]. Despite these contradictory data, which suggest that the polyAla FOXE1 tract should be studied in other populations, recent NGS-based studies in Chinese [6,13] and European [7,34] CH cohorts did not explore the association of polyAla FOXE1 alleles and/or genotypes with the risk of TD. This may reflect: the inherent difficulties of using NGS bioinformatics approaches to achieve accurate variant annotation in repetitive sequences, such as polyAla stretches; the high GC content of the FOXE1 gene ( 73\%), which could lead to a low sequencing depth and coverage (i.e., 51.7\%) [13]; and/or the inclusion of $\mathrm{CH}$ patients regardless of their thyroid 
phenotype $[6,7,13]$. Unlike the analysis carried out by Carré A et al. [14], which considered only the 14 and 16 alanine alleles and genotypes, our association approach encompassed all identified polyAla alleles and genotypes, including a novel 10 alanine allele and a rare 17 alanine allele. While a tendency for a protective effect was noted for alleles larger than 14 alanines and their genotypes, similar to that described for French Caucasian patients [14], this effect did not achieve statistical significance (Table 2). Thus, alleles larger or shorter that 14 alanines or their genotypes did not appear to influence the risk for developing CH-TD in our population. Future association analyses performed with larger samples of patients and controls among different ethnicities may identify strong and specific associations between polyAla FOXE1 stretches and specific thyroid phenotypes [14,52,53], sex [14], extra-thyroidal congenital defects [52], and/or familial CH-TD antecedents [53].

\section{Conclusions}

- Although the Mexican population has one of the highest worldwide $\mathrm{CH}$ birth prevalences, our results along with the previously published findings confirm that small nucleotide and clinically relevant germline variants in the main TD-related genes of PAX8 [18], NKX2-1 [19], FOXE1, NKX2-5, and TSHR account for a minority (2.5\%) of primary and permanent $\mathrm{CH}$ Mexican patients due to non-syndromic TD.

- Two previously unreported and clinically relevant genotypes, homozygous FOXE1 p.[Gly124Arg];[Gly124Arg] and compound heterozygous TSHR p.[Asp118Asn];[Trp422Arg], were found to account for $1.5 \%(\mathrm{~N}=2 / 128)$ of the $\mathrm{CH}-\mathrm{TD}$ patients, but further functional and segregation analyses are warranted.

- Unlike Polish CH patients [15], Mexican CH-TD patients did not harbor CNVs in PAX8, NKX2-1, FOXE1, or TSHR.

- Although we did not evaluate CNVs in NKX2-5, our data support the idea that it has negligible etiological participation in TD along with a benign character for its p.(Ala119Ser) allele [40].

- The protective effect on TD risk previously described for FOXE1 polyAla alleles larger than 16 alanines or their genotypes in French Caucasians [14] was not significantly supported in our Mexican CH-TD population.

Supplementary Materials: The following are available online at https:/ /www.mdpi.com/article/10 .3390/children8060457/s1, Table S1: PCR primer sequences and sequencing conditions.

Author Contributions: Conceptualization, M.A.A.-O., I.S.-V., A.G.-N. and A.G.-d.A.; data curation, M.A.A.-O., I.S.-V., L.F.-H., S.E.-F., N.L.H.-M. and A.G.-d.A.; formal analysis, M.A.A.-O., I.S.-V., L.F.-H., S.E.-F., A.G.-N., N.L.H.-M., C.S. and A.G.-d.A.; funding acquisition, M.A.A.-O., I.S.-V. and A.G.-d.A.; investigation, M.A.A.-O., I.S.-V., L.F.-H., A.G.-N., C.S. and A.G.-d.A.; methodology, M.A.A.-O., I.S.-V., L.F.-H., A.G.-N., N.L.H.-M. and A.G.-d.A.; project administration, M.A.A.-O. and A.G.-d.A.; resources, A.G.-d.A.; software, M.A.A.-O. and S.E.-F; supervision, A.G.-d.A.; validation, M.A.A.-O., I.S.-V., L.F.-H., N.L.H.-M., C.S. and A.G.-d.A.; writing-original draft, M.A.A.-O., I.S.-V. and A.G.-d.A.; writing-review \& editing, M.A.A.-O., I.S.-V., S.E.-F., A.G.-N., N.L.H.-M., C.S. and A.G.-d.A. All authors have read and agreed to the published version of the manuscript.

Funding: This research was funded by the Instituto Nacional de Pediatría, Secretaría de Salud (Recursos Fiscales 2015-2020, Programa E022 Investigación y Desarrollo Tecnológico en Salud, Ciudad de Mexico, Mexico) and Fondo Sectorial de Investigación en Salud y Seguridad Social SS/IMSS/ISSSTECONACyT (SALUD-2014-01-233654). We thank to Centro de Alta Especialidad en Genética Humana DNA-GEN SC, Mexico City, Mexico, for its support to cover the article processing charge.

Institutional Review Board Statement: The study was conducted according to the guidelines of the Declaration of Helsinki, and approved by the Institutional Review Research, Biosecurity and Ethics Committees of the National Institute of Pediatrics, Mexico (Registries 083/2013 and 058/2019).

Informed Consent Statement: Written informed consent was obtained from parents of all subjects involved in the study. 
Data Availability Statement: Publicly available datasets were analyzed in this study. This data can be found here: ClinVar: https:/ / www.ncbi.nlm.nih.gov/clinvar/, accessed on 8 March 2021; dbSNP: https:/ / www.ncbi.nlm.nih.gov/snp/, accessed on 8 March 2021; Genome Aggregation Database (gnomAD) v.2.1.1: https://gnomad.broadinstitute.org/, accessed on 27 May 2021; LOVD: https: / /www.lovd.nl/, accessed on 15 March 2021; OMIM: https:/ /www.omim.org/, accessed on 8 March 2021; NCBI: https: / / www.ncbi.nlm.nih.gov/gene, accessed on 8 March 2021; Protein Data Bank (PDB): http:/ / www.wwpdb.org/, accessed on 8 April 2021; UNIPROT: https:/ / www.uniprot.org/, accessed on 8 April 2021. The data presented in this study are available on reasonable request from the corresponding author. The clinical and molecular data of patients and their relatives are not publicly available due to restrictions to preserve their confidentiality, which was part of the signed informed consent of each patient. All the herein reported clinically relevant genetic variants along with the available deidentified phenotypic data were submitted to the publicly available database LOVD v.3.0 - Leiden Open Variation Database (https:/ / www.lovd.nl/, accessed on 15 March 2021).

Acknowledgments: M.A.A.-O. and A.G.-d.A. wish to dedicate this article to the memory of QFB Mario Arturo Maldonado Solís (1968-2021), a visionary and enthusiastic professional committed to Mexican children's health through carrying out high-quality newborn screening programs. I.S.-V. acknowledges the CONACYT post-graduate scholarship (CVU 519519, Programa de Maestría y Doctorado en Ciencias Médicas, Odontológicas y de la Salud, UNAM). The authors gratefully acknowledge the patients and parents for their commitment. They also thank Martínez-Cruz, V., Moreno-Rojas, R., Urióstegui-Rojas, A., and Alejandre-López, J.L. for their assistance with the recruitment and patient sampling processes, as well as data collection and technical support.

Conflicts of Interest: The authors declare no conflict of interest. The funders had no role in the design of the study; in the collection, analysis, or interpretation of data; in the writing of the manuscript; or in the decision to publish the results.

\section{References}

1. Lorey, F.W.; Cunningham, G.C. Birth prevalence of primary congenital hypothyroidism by sex and ethnicity. Hum. Biol. 1992, 64, 531-538. [PubMed]

2. Ford, G.; LaFranchi, S.H. Screening for congenital hypothyroidism: A worldwide view of strategies. Best Pract. Res. Clin. Endocrinol. Metab. 2014, 28, 175-187. [CrossRef] [PubMed]

3. Mio, C.; Grani, G.; Durante, C.; Damante, G. Molecular defects in thyroid dysgenesis. Clin. Genet. 2020, 97, 222-231. [CrossRef] [PubMed]

4. Castanet, M.; Polak, M.; Bonaïti-Pellié, C.; Lyonnet, S.; Czernichow, P.; Léger, J. Nineteen Years of National Screening for Congenital Hypothyroidism: Familial Cases with Thyroid Dysgenesis Suggest the Involvement of Genetic Factors. J. Clin. Endocrinol. Metab. 2001, 86, 2009-2014. [CrossRef] [PubMed]

5. Stoppa-Vaucher, S.; Van Vliet, G.; Deladoëy, J. Variation by Ethnicity in the Prevalence of Congenital Hypothyroidism Due to Thyroid Dysgenesis. Thyroid 2011, 21, 13-18. [CrossRef]

6. Yu, B.; Long, W.; Yang, Y.; Wang, Y.; Jiang, L.; Cai, Z.; Wang, H. Newborn Screening and Molecular Profile of Congenital Hypothyroidism in a Chinese Population. Front. Genet. 2018, 9, 509. [CrossRef]

7. Makretskaya, N.; Bezlepkina, O.; Kolodkina, A.; Kiyaev, A.; Vasilyev, E.V.; Petrov, V.; Kalinenkova, S.; Malievsky, O.; Dedov, I.I.; Tiulpakov, A. High frequency of mutations in 'dyshormonogenesis genes' in severe congenital hypothyroidism. PLoS ONE 2018, 13, e0204323. [CrossRef]

8. Hinojosa-Trejo, M.A.; Vela-Amieva, M.; Ibarra-González, I.; Cosío-Farias, A.P.; Herrera-Pérez, L.A.; Caamal-Parra, G.; BolañosCórdova, L.E.; García-Flores, E.P. Prevalencia al nacimiento de hipotiroidismo congénito. Acta Pediátr. Mexico 2018, 39 , 5-13. [CrossRef]

9. Kreisner, E.; Neto, E.; Gross, J. High Prevalence of Extrathyroid Malformations in a Cohort of Brazilian Patients with Permanent Primary Congenital Hypothyroidism. Thyroid 2005, 15, 165-169. [CrossRef]

10. Monroy-Santoyo, S.; Ibarra-González, I.; Fernández-Lainez, C.; Greenawalt-Rodríguez, S.; Chacón-Rey, J.; Calzada-León, R.; Vela-Amieva, M. Higher incidence of thyroid agenesis in Mexican newborns with congenital hypothyroidism associated with birth defects. Early Hum. Dev. 2012, 88, 61-64. [CrossRef]

11. Kumorowicz-Czoch, M.; Tylek-Lemanska, D.; Wyrobek, L.; Grodzicka, T.; Starzyk, J. Thyroid developmental anomalies among first-degree relatives of children with thyroid dysgenesis and congenital hypothyroidism. J. Pediatr. Endocrinol. Metab. 2012, 25, 413-418. [CrossRef]

12. Sindhuja, L.; Dayal, D.; Sodhi, K.S.; Sachdeva, N.; Bhattacharya, A. Thyroid dysfunction and developmental anomalies in first degree relatives of children with thyroid dysgenesis. World J. Pediatr. 2016, 12, 215-218. [CrossRef]

13. Sun, F.; Zhang, J.-X.; Yang, C.-Y.; Gao, G.-Q.; Zhu, W.-B.; Han, B.; Zhang, L.-L.; Wan, Y.-Y.; Ye, X.-P.; Ma, Y.-R.; et al. The genetic characteristics of congenital hypothyroidism in China by comprehensive screening of 21 candidate genes. Eur. J. Endocrinol. 2018, 178, 623-633. [CrossRef] [PubMed] 
14. Carré, A.; Castanet, M.; Sura-Trueba, S.; Szinnai, G.; Van Vliet, G.; Trochet, D.; Amiel, J.; Léger, J.; Czernichow, P.; Scotet, V.; et al. Polymorphic length of FOXE1 alanine stretch: Evidence for genetic susceptibility to thyroid dysgenesis. Hum. Genet. 2007, 122, 467-476. [CrossRef]

15. Kumorowicz-Czoch, M.; Madetko-Talowska, A.; Tylek-Lemanska, D.; Pietrzyk, J.J.; Starzyk, J. Identification of deletions in children with congenital hypothyroidism and thyroid dysgenesis with the use of multiplex ligation-dependent probe amplification. J. Pediatr. Endocrinol. Metab. 2015, 28, 171-176. [CrossRef] [PubMed]

16. Narumi, S.; Muroya, K.; Asakura, Y.; Adachi, M.; Hasegawa, T. Transcription Factor Mutations and Congenital Hypothyroidism: Systematic Genetic Screening of a Population-Based Cohort of Japanese Patients. J. Clin. Endocrinol. Metab. 2010, 95, 1981-1985. [CrossRef]

17. Vela-Amieva, M.; Gamboa-Cardiel, S.; Pérez-Andrade, E.M.; Ortiz-Cortés, J.; González-Contreras, C.R.; Ortega-Velázquez, V. Epidemiología del hipotiroidismo congénito en Mexico. Salud Pública Mexico 2004, 46, 141-148. [CrossRef]

18. Alcántara-Ortigoza, M.A.; Angel, A.G.-D.; Martínez-Cruz, V.; Vela-Amieva, M.; Sánchez-Pérez, C.; Moreno-Rojas, R.; EstandíaOrtega, B.; Hernández-Martínez, N. Molecular analysis of the PAX8 gene in a sample of Mexican patients with primary congenital hypothyroidism: Identification of the recurrent p.Arg31His mutation. Clin. Endocrinol. 2012, 76, 148-150. [CrossRef]

19. González-del Angel, A.; Fernández-Hernández, L.; Sánchez-Verdiguel, I.; González-Núñez, A.; Martínez-Cruz, V.; Sánchez, C.; Moreno-Rojas, R.; Alcántara-Ortigoza, M.A. Gene Variants in NKX2-1 Do Not Represent a Major Etiological Factor of Primary Congenital Hypothyroidism in Mexican Population. J. Pediatr. Genet. 2019, 8, 41-46. [CrossRef]

20. Richards, S.; Aziz, N.; Bale, S.; Bick, D.; Das, S.; Gastier-Foster, J.; Grody, W.W.; Hegde, M.; Lyon, E.; Spector, E.; et al. Standards and guidelines for the interpretation of sequence variants: A joint consensus recommendation of the American College of Medical Genetics and Genomics and the Association for Molecular Pathology. Genet. Med. 2015, 17, 405-423. [CrossRef] [PubMed]

21. Kleinberger, J.; Maloney, K.; Pollin, T.I.; Jeng, L.J.B. An openly available online tool for implementing the ACMG/AMP standards and guidelines for the interpretation of sequence variants. Genet. Med. 2016, 18, 1165. [CrossRef] [PubMed]

22. Yang, J.; Yan, R.; Roy, A.; Xu, D.; Poisson, J.; Zhang, Y. The I-TASSER Suite: Protein structure and function prediction. Nat. Methods 2015, 12, 7-8. [CrossRef] [PubMed]

23. Wu, S.; Zhang, Y. LOMETS: A local meta-threading-server for protein structure prediction. Nucleic Acids Res. 2007, 35, 3375-3382. [CrossRef]

24. Tsai, K.-L.; Huang, C.-Y.; Chang, C.-H.; Sun, Y.-J.; Hsiao, C.-D. Crystal Structure of the Human FOXK1a-DNA Complex and Its Implications on the Diverse Binding Specificity of Winged Helix/Forkhead Proteins. J. Biol. Chem. 2006, 281, 17400-17409. [CrossRef] [PubMed]

25. Sanders, P.; Young, S.; Sanders, J.; Kabelis, K.; Baker, S.; Sullivan, A.; Evans, M.; Clark, J.; Wilmot, J.; Hu, X.; et al. Crystal structure of the TSH receptor bound to a blocking type TSHR autoantibody. J. Mol. Endocrinol. 2011, 46, 81-99. [CrossRef]

26. Pettersen, E.F.; Goddard, T.D.; Huang, C.C.; Couch, G.S.; Greenblatt, D.M.; Meng, E.C.; Ferrin, T.E. UCSF Chimera-A visualization system for exploratory research and analysis. J. Comput. Chem. 2004, 25, 1605-1612. [CrossRef]

27. Williams, C.J.; Headd, J.J.; Moriarty, N.W.; Prisant, M.G.; Videau, L.L.; Deis, L.N.; Verma, V.; Keedy, D.A.; Hintze, B.; Chen, V.B.; et al. MolProbity: More and better reference data for improved all-atom structure validation. Protein Sci. 2018, 27, 293-315. [CrossRef]

28. Jo, S.; Kim, T.; Iyer, V.G.; Im, W. CHARMM-GUI: A web-based graphical user interface for CHARMM. J. Comput. Chem. 2008, 29, 1859-1865. [CrossRef]

29. Omasits, U.; Ahrens, C.; Müller, S.; Wollscheid, B. Protter: Interactive protein feature visualization and integration with experimental proteomic data. Bioinformatics 2014, 30, 884-886. [CrossRef]

30. Humphrey, W.; Dalke, A.; Schulten, K. VMD: Visual molecular dynamics. J. Mol. Graph. 1996, 14, 33-38. [CrossRef]

31. Cerqueira, T.L.D.O.; Ramos, Y.R.; Strappa, G.B.; De Jesus, M.S.; Santos, J.G.; Sousa, C.; Carvalho, G.; Fernandes, V.; Boa-Sorte, N.; Amorim, T.; et al. Mutation screening in the genes PAX-8, NKX2-5, TSH-R, HES-1 in cohort of 63 Brazilian children with thyroid dysgenesis. Arch. Endocrinol. Metab. 2018, 62, 466-471. [CrossRef]

32. Brust, E.S.; Beltrao, C.B.; Chammas, M.C.; Watanabe, T.; Sapienza, M.T.; Marui, S. Absence of mutations in PAX8, NKX2.5, and TSH receptor genes in patients with thyroid dysgenesis. Arq. Bras. Endocrinol. Metabol. 2012, 56, 173-177. [CrossRef] [PubMed]

33. Léger, J.; Olivieri, A.; Donaldson, M.; Torresani, T.; Krude, H.; Van Vliet, G.; Polak, M.; Butler, G. European Society for Paediatric Endocrinology Consensus Guidelines on Screening, Diagnosis, and Management of Congenital Hypothyroidism. Horm. Res. Paediatr. 2014, 81, 80-103. [CrossRef]

34. Santos-Silva, R.; Rosário, M.; Grangeia, A.; Costa, C.; Castro-Correia, C.; Alonso, I.; Leão, M.; Fontoura, M. Genetic analyses in a cohort of Portuguese pediatric patients with congenital hypothyroidism. J. Pediatr. Endocrinol. Metab. 2019, 32, 1265-1273. [CrossRef] [PubMed]

35. Löf, C.; Patyra, K.; Kuulasmaa, T.; Vangipurapu, J.; Undeutsch, H.; Jaeschke, H.; Pajunen, T.; Kero, A.; Krude, H.; Biebermann, H.; et al. Detection of Novel Gene Variants Associated with Congenital Hypothyroidism in a Finnish Patient Cohort. Thyroid 2016, 26, 1215-1224. [CrossRef] [PubMed]

36. Long, W.; Zhou, L.; Wang, Y.; Liu, J.; Wang, H.; Yu, B. Complicated Relationship between Genetic Mutations and Phenotypic Characteristics in Transient and Permanent Congenital Hypothyroidism: Analysis of Pooled Literature Data. Int. J. Endocrinol. 2020, 2020, 1-8. [CrossRef] [PubMed]

37. Castanet, M.; Polak, M. Spectrum of Human Foxe1/TTF2 Mutations. Horm. Res. Paediatr. 2010, 73, 423-429. [CrossRef] 
38. Dentice, M.; Cordeddu, V.; Rosica, A.; Ferrara, A.M.; Santarpia, L.; Salvatore, L.C.D.; Chiovato, L.; Perri, A.; Moschini, L.; Fazzini, C.; et al. Missense Mutation in the Transcription Factor NKX2-5: A Novel Molecular Event in the Pathogenesis of Thyroid Dysgenesis. J. Clin. Endocrinol. Metab. 2006, 91, 1428-1433. [CrossRef]

39. Al Taji, E.; Biebermann, H.; Límanová, Z.; Hníková, O.; Zikmund, J.; Dame, C.; Grüters, A.; Lebl, J.; Krude, H. Screening for mutations in transcription factors in a Czech cohort of 170 patients with congenital and early-onset hypothyroidism: Identification of a novel PAX8 mutation in dominantly inherited early-onset non-autoimmune hypothyroidism. Eur. J. Endocrinol. 2007, 156, 521-529. [CrossRef]

40. Van Engelen, K.; Mommersteeg, M.T.M.; Baars, M.J.H.; Lam, J.; Ilgun, A.; Van Trotsenburg, A.S.P.; Smets, A.M.J.B.; Christoffels, V.M.; Mulder, B.J.M.; Postma, A.V. The Ambiguous Role of NKX2-5 Mutations in Thyroid Dysgenesis. PLoS ONE 2012, 7, e52685. [CrossRef]

41. Khatami, M.; Heidari, M.M.; Tabesh, F.; Ordooei, M.; Salehifar, Z. Mutation analysis of the NKX2.5 gene in Iranian pediatric patients with congenital hypothyroidism. J. Pediatr. Endocrinol. Metab. 2017, 30, 857-862. [CrossRef] [PubMed]

42. Hermanns, P.; Grasberger, H.; Refetoff, S.; Pohlenz, J. Mutations in the NKX2.5 Gene and the PAX8 Promoter in a Girl with Thyroid Dysgenesis. J. Clin. Endocrinol. Metab. 2011, 96, E977-E981. [CrossRef] [PubMed]

43. Persani, L.; Calebiro, D.; Cordella, D.; Weber, G.; Gelmini, G.; Libri, M.; De Filippis, T.; Bonomi, M. Genetics and phenomics of hypothyroidism due to TSH resistance. Mol. Cell. Endocrinol. 2010, 322, 72-82. [CrossRef] [PubMed]

44. Szidonya, L.; Cserző, M.; Hunyady, L. Dimerization and oligomerization of G-protein-coupled receptors: Debated structures with established and emerging functions. J. Endocrinol. 2008, 196, 435-453. [CrossRef]

45. Latif, R.; Michalek, K.; Morshed, S.A.; Davies, T.F. A Tyrosine Residue on the TSH Receptor Stabilizes Multimer Formation. PLoS ONE 2010, 5, e9449. [CrossRef]

46. Smits, G.; Campillo, M.; Govaerts, C.; Janssens, V.; Richter, C.; Vassart, G.; Pardo, L.; Costagliola, S. Glycoprotein hormone receptors: Determinants in leucine-rich repeats responsible for ligand specificity. EMBO J. 2003, 22, 2692-2703. [CrossRef]

47. Lábadi, Á.; Grassi, E.S.; Gellén, B.; Kleinau, G.; Biebermann, H.; Ruzsa, B.; Gelmini, G.; Rideg, O.; Miseta, A.; Kovács, G.L.; et al. Loss-of-Function Variants in a Hungarian Cohort Reveal Structural Insights on TSH Receptor Maturation and Signaling. J. Clin. Endocrinol. Metab. 2015, 100, E1039-E1045. [CrossRef]

48. Ruchała, M.; Szczepanek, E.; Sowiński, J. Diagnostic value of radionuclide scanning and ultrasonography in thyroid developmental anomaly imaging. Nucl. Med. Rev. Cent. East Eur. 2011, 14, 21-28. [CrossRef]

49. Camilot, M.; Teofoli, F.; Gandini, A.; Franceschi, R.; Rapa, A.; Corrias, A.; Bona, G.; Radetti, G.; Tatò, L. Thyrotropin receptor gene mutations and TSH resistance: Variable expressivity in the heterozygotes. Clin. Endocrinol. 2005, 63, 146-151. [CrossRef]

50. Zdraveska, N.; Kocova, M.; Nicholas, A.K.; Anastasovska, V.; Schoenmakers, N. Genetics of Gland-in-situ or Hypoplastic Congenital Hypothyroidism in Macedonia. Front. Endocrinol. 2020, 11, 413. [CrossRef]

51. Nicholas, A.K.; Serra, E.G.; Cangul, H.; Alyaarubi, S.; Ullah, I.; Schoenmakers, E.; Deeb, A.; Habeb, A.M.; Almaghamsi, M.; Peters, C.; et al. Comprehensive Screening of Eight Known Causative Genes in Congenital Hypothyroidism with Gland-in-Situ. J. Clin. Endocrinol. Metab. 2016, 101, 4521-4531. [CrossRef] [PubMed]

52. Santarpia, L.; Valenzise, M.; Di Pasquale, G.; Arrigo, T.; Martino, G.S.; Cicciò, M.P.; Trimarchi, F.; De Luca, F.; Benvenga, S. TTF-2/FOXE1 gene polymorphisms in Sicilian patients with permanent primary congenital hypothyroidism. J. Endocrinol. Investig. 2007, 30, 13-19. [CrossRef] [PubMed]

53. Szczepanek, E.; Ruchala, M.; Szaflarski, W.; Budny, B.; Kilinska, L.; Jaroniec, M.; Niedziela, M.; Zabel, M.; Sowiński, J. FOXE1 Polyalanine Tract Length Polymorphism in Patients with Thyroid Hemiagenesis and Subjects with Normal Thyroid. Horm. Res. Paediatr. 2011, 75, 329-334. [CrossRef] [PubMed] 